\title{
Exploiting Carbonyl Groups to Control Intermolecular Rhodium- Catalyzed Alkene and Alkyne Hydroacylation
}

\author{
Thomas J. Coxon, Maitane Fernández, James Barwick-Silk, Alasdair I. McKay, Louisa E. Britton,
} Andrew S. Weller, ${ }^{\circledR}$ and Michael C. Willis*i)

Department of Chemistry, Chemistry Research Laboratory, University of Oxford, Mansfield Road, Oxford OX1 3TA, U.K.

\section{Supporting Information}

ABSTRACT: Readily available $\beta$-carbonyl-substituted aldehydes are shown to be exceptional substrates for Rh-catalyzed intermolecular alkene and alkyne hydroacylation reactions. By using cationic rhodium catalysts incorporating bisphosphine ligands, efficient and selective reactions are achieved for $\beta$ amido, $\beta$-ester, and $\beta$-keto aldehyde substrates, providing a range of synthetically useful 1,3-dicarbonyl products in excellent yields. A correspondingly broad selection of alkenes and alkynes can be employed. For alkyne substrates, the use of a catalyst incorporating the Ampaphos ligand triggers a regioselectivity switch, allowing both linear and branched isomers to be prepared with high selectivity in an efficient manner. Structural data, confirming aldehyde chelation, and a proposed mechanism are provided.

\section{INTRODUCTION}

The development of reactions based on metal-catalyzed functionalization of $\mathrm{C}-\mathrm{H}$ bonds is revolutionizing organic synthesis and is delivering a series of nontraditional bond constructions as reliable synthetic tools. ${ }^{1}$ Metal-catalyzed alkene and alkyne hydroacylation reactions, in which a $\mathrm{C}-\mathrm{C}$ multiple bond is formally inserted into the formyl $\mathrm{C}-\mathrm{H}$ bond of aldehydes, are examples of such nontraditional reactions and are becoming established as synthetically useful processes. ${ }^{2}$ Although a small number of nonchelation-controlled methods have been developed, ${ }^{3,4}$ as have reactions based on the use of carboxylic acid derivatives under reducing conditions, ${ }^{5}$ the majority of metal catalyzed hydroacylation reactions employ some form of substrate chelation as this has proven to be an effective strategy to attenuate undesirable reductive-decarbonylation pathways (Scheme 1a). In addition, chelation-controlled processes often benefit from mild reaction conditions and an increased substrate scope. Lochow and Miller first introduced this concept when they employed an aldehyde containing a pendant alkene as a coordinating group, to promote an intermolecular alkene hydroacylation reaction. ${ }^{6}$ More recently, aldehydes featuring $\mathrm{P}-_{-},{ }^{7} \mathrm{O}-{ }_{-}{ }^{8} \mathrm{~N}-{ }^{9},{ }^{9}$ and S-based chelating groups have all been reported (Scheme 1b). ${ }^{10}$ Chelating alkene substrates have also been employed effectively. ${ }^{11}$ Collectively, these chelation-based methods have allowed significant advances, including the development of regio- ${ }^{8 \mathrm{e}, 12}$ and enantioselective reactions, ${ }^{8 \mathrm{a}, 13}$ as well as applications in target synthesis. $^{14}$

The caveat to the success of these chelation-based reactions is that the chelating group is present in the products; ${ }^{15}$ strategies to address this include incorporating the coordinating atom or group into a target structure, often a heterocy- cle, ${ }^{8 b, 9 a, 11 b, 14 a}$ or transforming the group by a second, frequently in situ, ${ }^{16}$ transformation. ${ }^{14 \mathrm{~d}}$ However, these manipulations could be avoided if the chelating unit was a common, synthetically valuable functional group, desired in a broad range of structures. When considering possible candidates to satisfy these criteria, the carbonyl group is the standout choice; carbonyl groups are arguably the most versatile functional groups in organic synthesis, and in addition to participating in a host of synthetically useful transformations they also feature in numerous designed molecules and natural products (Scheme 1c). In this Article we show for the first time how simple carbonyl groups such as amides, esters, and ketones can perform as effective chelating groups and deliver alkene and alkyne hydroacylation reactions of exceptional scope and utility.

\section{RESULTS AND DISCUSSION}

Although carbonyl groups are well established as directing groups in a number of $\mathrm{C}-\mathrm{H}$ functionalization protocols, ${ }^{17}$ they have not been employed in hydroacylation chemistry. Guided by the topology of previously successful chelating aldehydes (Scheme 1b), we envisioned that 1,3-dicarbonyl arrangements would provide effective motifs for rhodium-catalyzed hydroacylation. To examine this hypothesis we initially evaluated a range of known hydroacylation catalysts in the coupling reaction between $\beta$-amido aldehyde $1 \mathbf{a}^{18}$ and 1-octyne (Scheme 2 ). It was apparent that excellent conversions and yields could be achieved using several catalysts. The main variation observed was in the regioselectivity of the transformation, with both the linear $(\mathbf{2} \mathbf{a}(1))$ and branched isomers $(\mathbf{2} \mathbf{a}(\mathbf{b}))$ being formed in

Received: June 2, 2017

Published: July 17, 2017 
Scheme 1. (a) Chelation-Controlled Intermolecular Hydroacylation, (b) Common Chelating Motifs, and (c) $\beta$ Carbonyl Aldehydes in Hydroacylation, with Representative $\beta$-Dicarbonyl Target Molecules

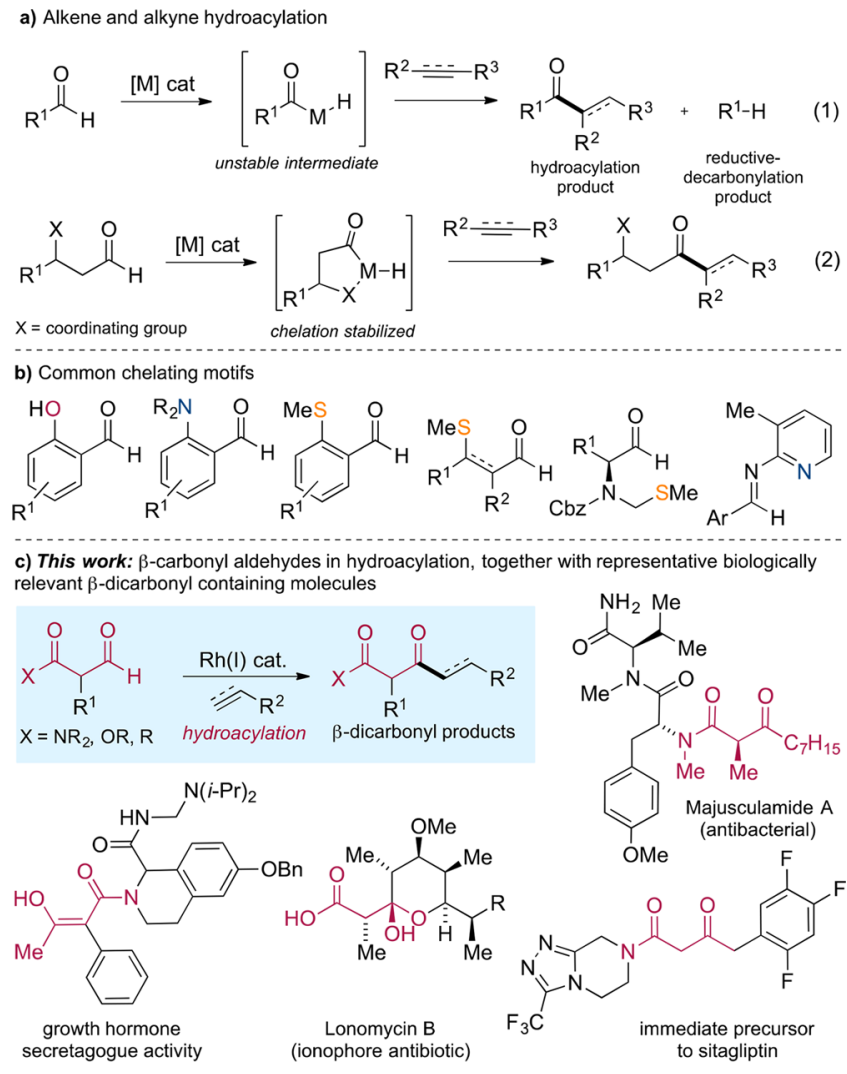

Scheme 2. Initial Ligand Evaluation for the Hydroacylation 1-Octyne Using Amido Aldehyde 1a ${ }^{a}$

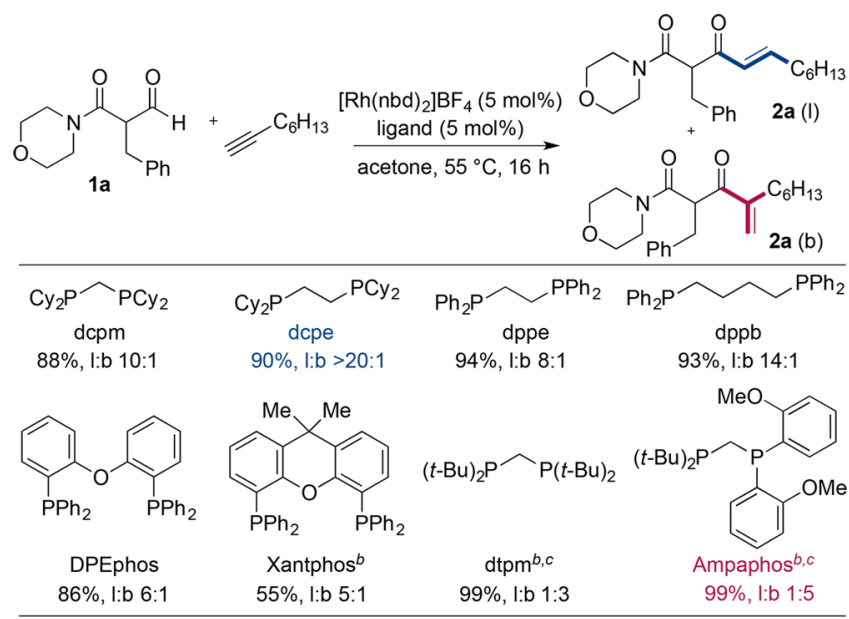

${ }^{a}$ Reaction conditions: 1a (1.0 equiv), 1-octyne (1.2 equiv), [Rh$\left.(\mathrm{nbd})_{2}\right] \mathrm{BF}_{4}(5 \mathrm{~mol} \%)$, ligand $(5 \mathrm{~mol} \%)$, acetone, $55{ }^{\circ} \mathrm{C}$, $16 \mathrm{~h}$. Isolated yields. ${ }^{b} 10 \mathrm{~mol} \% \mathrm{Rh}$ and ligand. Conversions. ${ }^{c}$ Used as the preformed complexes $\left[\mathrm{Rh}(\mathrm{dtpm})\left(\mathrm{C}_{6} \mathrm{H}_{5} \mathrm{~F}\right)\right]\left[\mathrm{BAr}^{\mathrm{F}}{ }_{4}\right]$ and $[\mathrm{Rh}$ (Ampaphos) $\left.\left(\mathrm{C}_{6} \mathrm{H}_{5} \mathrm{~F}\right)\right]\left[\mathrm{BAr}_{4}^{\mathrm{F}}\right]$, respectively. $\mathrm{Ar}^{\mathrm{F}}=\mathrm{C}_{6} \mathrm{H}_{3}-3,5-\left(\mathrm{CF}_{3}\right)_{2}$.

some cases. Small bite angle ligands such as dcpm and dppm, ${ }^{19}$ which deliver the greatest linear selectivity for $\beta$-S-chelating aldehydes, only provided moderate selectivity when using amido aldehyde 1a. Interestingly, the sterically congested small bite angle ligands Ampaphos and dtpm exhibited a preference for the branched isomer. ${ }^{20}$ The most efficient and selective system for the formation of the linear isomer was achieved using a dcpe-derived catalyst at $5 \mathrm{~mol} \%$ loading, delivering $\beta$ keto amide 2 a in $90 \%$ isolated yield with $>20: 1$ regioselectivity.

Using this catalyst system we next examined the scope of the transformation with respect to different alkynes and $\beta$-amido aldehydes (Table 1). Isolated yields were consistently high when aldehyde 1a was combined with a range of terminal alkynes. The use of phenyl acetylene derivatives with both electron-donating and electron-withdrawing groups $(\mathbf{2} \mathbf{b}-\mathbf{d})$ was well tolerated. A broad range of alkyl substitution patterns, including branching and carbocycles, could be incorporated $(2 \mathrm{e}-\mathrm{k})$. Furthermore, a wide variety of alkynes containing different functional groups, including nitrile, chloro, alcohol, acetal, and ether substituents, were successfully employed (21r). The reaction between aldehyde 1a with 3-butyn-2-ol delivered saturated ketone $\mathbf{2 r}$ as the product, resulting from a rhodium-catalyzed isomerization of the initially formed enone.

Having demonstrated the robustness of the methodology toward variation of the alkyne partner, we next examined a series of $\beta$-amido aldehydes. Variation of the substituent at the $\alpha$-carbon was achieved without incident, allowing the incorporation of various aryl, alkyl, and alkenyl substituents $(2 s-z)$. In addition, $\alpha, \alpha$-disubstitution was also possible and had minimal effect on reaction efficiency (2aa-ab). We then explored the use of amides with different substitutions at the nitrogen atom, and a variety of cyclic and noncyclic secondary amines performed extremely well in reactions with 1-octyne (entries 2ac-ae), as did a Weinreb amide (2af). We were pleased to observe that the presence of a free $\mathrm{N}-\mathrm{H}$ bond did not compromise reactivity (2ag). This observation led to the use of a phenyl alanine-derived aldehyde, which delivered coupled product $\mathbf{2 a h}$ in excellent yield and enantiopurity. Finally, a cyclic $\beta$-amido aldehyde was also subjected to the hydroacylation conditions and provided the 2-piperidone-based product 2ai in excellent yield. All of the transformations described above were performed using a $5 \mathrm{~mol} \%$ catalyst loading; however, it was possible to reduce this to only $0.5 \mathrm{~mol}$ $\%$ when larger-scale reactions were conducted (see $\mathbf{2 a}$ ).

With a robust method to deliver linear $\beta$-amido enones established, we next explored the possibility of selectively accessing the corresponding branched isomers. Further optimization from our initial result employing an Ampaphosderived catalyst (Scheme 2) allowed a selective process to be developed. The optimal conditions involved performing the reactions at lower temperature $\left(-20{ }^{\circ} \mathrm{C}\right.$ versus $\left.55{ }^{\circ} \mathrm{C}\right)$ and increased concentration $(2.0 \mathrm{M}$ versus $1.0 \mathrm{M})$, and these were then applied to a series of alkynes and aldehydes (Table 2). The scope of the branched selective hydroacylation of alkynes proved less general than in the case of the linear selective reaction; however, a wide range of alkynes and aldehydes could still be successfully employed. Methyl-substituted amido aldehyde 1d provided high selectivity with aliphatic alkynes, including a chloro-substituted example $(3 \mathbf{a}-\mathbf{d})$. However, the use of $\mathrm{sp}^{2}$-C-substituted alkynes resulted in a significant drop in selectivity, although the branched isomer was still the major component $(3 \mathbf{e}, \mathbf{f})$. The $\alpha$-substituent of the amido aldehyde substrates could be modified without significantly influencing the outcome of the reactions, with a range of substituents of varied steric profile being tolerated $(3 g-1)$. Finally, the use of alternative amido groups provided the desired branched products with excellent selectivities $(3 \mathbf{m}, \mathbf{n})$. 
Table 1. Linear Selective Alkyne Hydroacylation Using $\beta$-Amido Aldehydes ${ }^{a}$

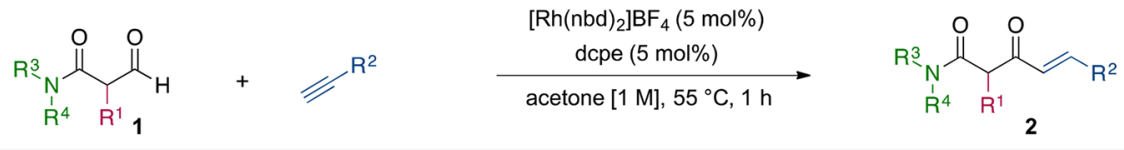

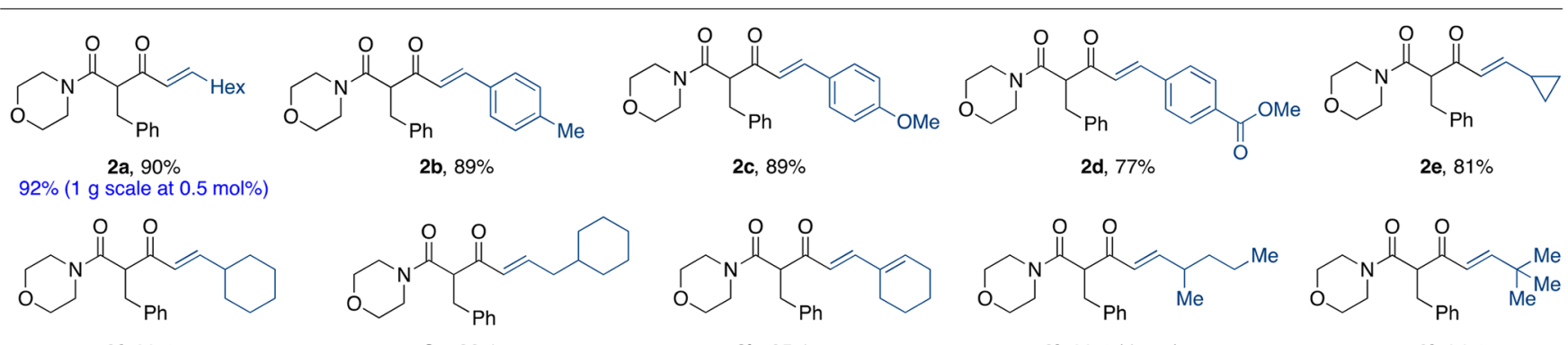

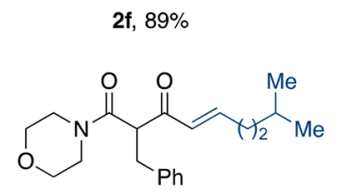

2k, $97 \%$<smiles>CC(C=CC(=O)C(Cc1ccccc1)C(=O)N1CCOCC1)c1ccccc1</smiles>

2p, $87 \%(d r 1: 1)$

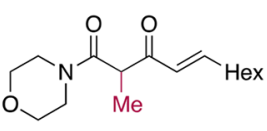

2u, $77 \%$<smiles>[R10]C=CC(=O)C(CC=C)C(=O)N1CCOCC1</smiles>

2z, $67 \%$<smiles>CN(C)C(=O)C(Cc1ccccc1)C(=O)/C=C/C=[W]</smiles>

2ae, $94 \%$<smiles>N#CCCCC=CC(=O)C(Cc1ccccc1)C(=O)N1CCOCC1</smiles>

2l, $72 \%$<smiles>CS/C=C/C(=O)C(Cc1ccccc1)C(=O)N1CCOCC1</smiles>

$2 q, 92 \%$<smiles>[R10]C=CC(=O)C(C(=O)N1CCOCC1)C(C)C</smiles>

2v, $92 \%$<smiles>[R10]C=CC(=O)C1(C(=O)N2CCOCC2)CCCC1</smiles>

2aa, 95\%

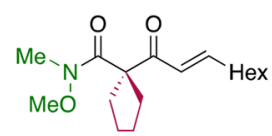

2af, $98 \%$<smiles>O=C(/C=C/CCCCl)C(Cc1ccccc1)C(=O)N1CCOCC1</smiles>

2m, $90 \%$<smiles>CC(=O)CCC(=O)C(Cc1ccccc1)C(=O)N1CCOCC1</smiles>

$2 r,{ }^{b} 57 \%$<smiles>[R10]C=CC(=O)C(C(=O)N1CCOCC1)C1CCCCC1</smiles>

$$
\text { 2w, } 87 \%
$$<smiles>[R4]C=CC(=O)C([Y4])(Cc1ccccc1)C(=O)N1CCOCC1</smiles>

2ab, $92 \%$<smiles>[R10]C=CC(=O)C1(C(=O)NCc2ccccc2)CCCC1</smiles>

2ag, $88 \%$<smiles>CC(O)CC=CC(=O)C(Cc1ccccc1)C(=O)N1CCOCC1</smiles>

2n, $74 \%(d r 1: 1)$<smiles>COc1ccc(CC(C(=O)/C=C/[18O])C(=O)N2CCOCC2)cc1OC</smiles><smiles>[R]C=CC(=O)C(CCOCc1ccccc1)C(=O)N1CCOCC1</smiles><smiles></smiles>

2ac, $93 \%$<smiles>COC(=O)C(Cc1ccccc1)NC(=O)C1(C(=O)/C=C/C=[W])CCCC1</smiles><smiles>CCOC(C=CC(=O)C(CC)OCC)C(=O)N1CCOCC1</smiles>

2o, $90 \%$<smiles>[R4][14CH2]/C=C/C(=O)[C@H](Cc1cccc2cccc([R16])c12)C(=O)N1CCOCC1</smiles><smiles>O=C(/C=C/[18O])C(C(=O)N1CCOCC1)c1ccccc1</smiles><smiles>[14CH3]/C=C/C(=O)C(Cc1ccccc1)C(C(=O)O)C(=O)N1CCCC1</smiles>

2ad, $94 \%$<smiles>CC1(C(=O)/C=C/[Ga])CCCN(OCc2ccccc2)C1=O</smiles>

2ai, $98 \%$

${ }^{a}$ Reaction conditions: 1 (1.0 equiv), alkyne (1.2 equiv), $\left[\mathrm{Rh}(\mathrm{nbd})_{2}\right] \mathrm{BF}_{4}(5 \mathrm{~mol} \%)$, dcpe $(5 \mathrm{~mol} \%)$, acetone, $55^{\circ} \mathrm{C}, 1 \mathrm{~h}$. Isolated yields of single isomers. ${ }^{b}$-Butyn-2-ol used as substrate.

Initial attempts to employ internal alkynes as substrates yielded mixed results; reaction of 1-phenyl-1-propane under the optimal conditions for the linear selective reaction promoted complete conversion of the aldehyde, although a 2:1 mixture of regioisomers was obtained. Re-evaluation of diphosphine ligands showed that several were able to promote complete conversion. However, DPEphos was unique in also providing control of the regioselectivity of the reaction, delivering an isolated yield of the linear isomer of enone $\mathbf{4 a}$ of $73 \%$ (Table 3 ). These conditions were applied to a variety of internal alkynes, including nonsymmetric alkynes possessing ester, ketone, and branched alkyl groups adjacent to the triple bond $(\mathbf{4 a}-\mathbf{f})$. Interestingly, when ethyl non-2-ynoate was employed, the selectivity could be completely switched by substituting DPEphos for the ligand dcpe, enabling the formation of both isomers selectively. When applied to alternative substrates, the dcpe-derived catalyst was generally poorly effective. Finally, good to excellent yields were achieved with symmetrical alkynes $(\mathbf{4 g}-\mathbf{i})$, including the hydroacylation of diphenylacetylene, which has proved a challenging substrate to combine with other classes of aldehydes. ${ }^{21}$

Having established mild and effective conditions for alkyne hydroacylation using $\beta$-amido aldehydes, we next focused on expanding the methodology to the hydroacylation of alkenes. In general, alkene hydroacylation has proved far more challenging than alkyne hydroacylation, often necessitating higher catalyst loadings, very specific ligand requirements, or the use of activated substrates. Considering these precedents, several catalyst systems were re-explored for the hydroacylation of 1octene with $\beta$-amido aldehyde $\mathbf{1 m}$ (Scheme 3 ). The reactivity varied considerably compared to the alkyne reactions, with only the ligands dppm and dcpm providing any conversion to the hydroacylation adduct; however, overall this was significantly reduced. Most importantly, for the first time since we started 
Table 2. Branched Selective Alkyne Hydroacylation Using $\beta$ Amido Aldehydes ${ }^{a}$

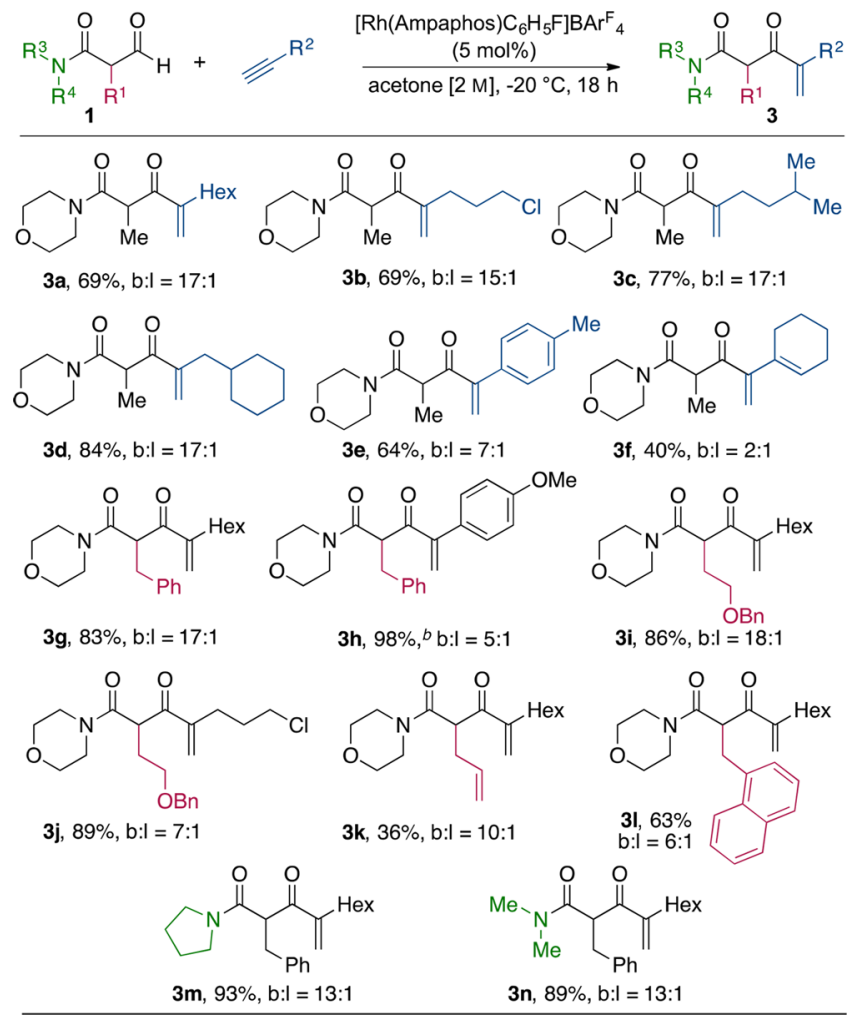

${ }^{a}$ Reaction conditions: aldehyde (1.0 equiv), alkyne (1.2 equiv), $\left[\mathrm{Rh}\right.$ (Ampaphos) $\left.\left(\mathrm{C}_{6} \mathrm{H}_{5} \mathrm{~F}\right)\right]\left[\mathrm{BAr}_{4}^{\mathrm{F}}\right](5 \mathrm{~mol} \%)$, acetone $[2.0 \mathrm{M}],-20$ ${ }^{\circ} \mathrm{C}, 18 \mathrm{~h} . \mathrm{Ar}^{\mathrm{F}}=\mathrm{C}_{6} \mathrm{H}_{3}-3,5-\left(\mathrm{CF}_{3}\right)_{2}$. Isolated yields of branched products. Selectivities determined by ${ }^{1} \mathrm{H}$ NMR spectroscopy of unpurified reaction mixtures. ${ }^{b}$ Isolated as an inseparable mixture of $1+b$ isomers.

Table 3. Hydroacylation of Internal Alkynes Using $\boldsymbol{\beta}$-Amido Aldehyde $1 \mathrm{a}^{a}$
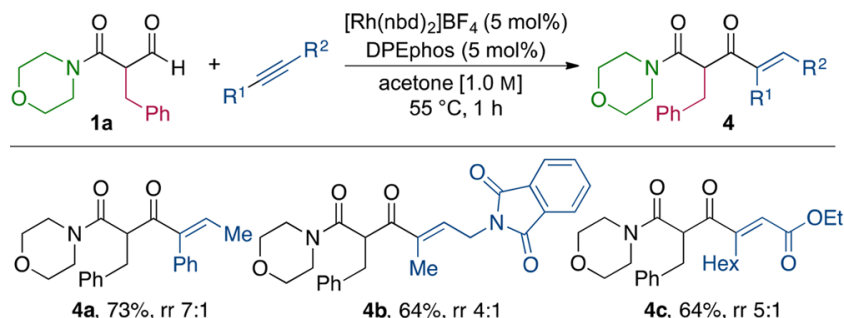

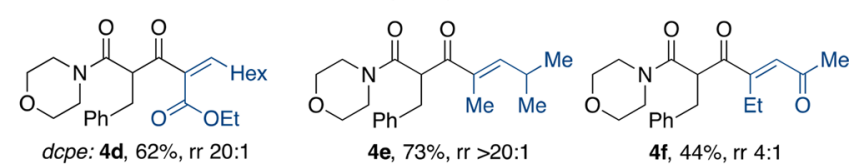

$$
\text { (N), }
$$

$a_{\mathrm{rr}}=$ regioisomer ratio. Reaction conditions: 1a (1.0 equiv), alkyne (1.2 equiv), $\left[\mathrm{Rh}(\mathrm{nbd})_{2}\right] \mathrm{BF}_{4}(5 \mathrm{~mol} \%)$, DPEphos (5 mol \%), acetone $[1.0 \mathrm{M}], 55{ }^{\circ} \mathrm{C}, 1 \mathrm{~h}$. Isolated yields of single isomers. Selectivities determined by ${ }^{1} \mathrm{H}$ NMR spectroscopy of unpurified reaction mixtures.

our investigations with this class of aldehydes, the presence of two side products was observed in the reaction mixture: decarbonylation product 6 and Tischenko-style dimerization
Scheme 3. Evaluation of Alkene Hydroacylation Using Mono- and Disubstituted Aldehydes ${ }^{a}$

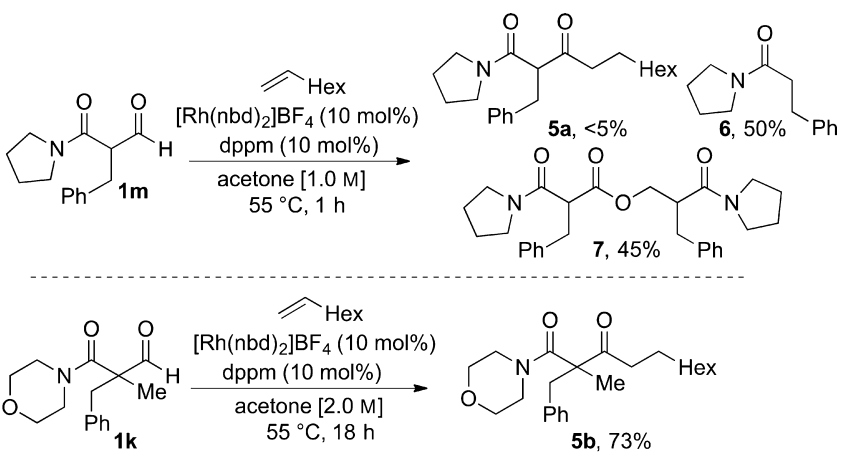

${ }^{a}$ Conversions measured by ${ }^{1} \mathrm{H}$ NMR spectroscopy.

product 7. The presence of these two compounds indicated a probable, relatively rapid, $\mathrm{C}-\mathrm{H}$ activation that is followed by a trifurcation of possible pathways: productive alkene hydroacylation, unproductive aldehyde hydroacylation and reductive decarbonylation. Further investigation showed that the use of $\alpha, \alpha$-disubstituted aldehydes completely suppressed these latter two side reactions. For example, reaction of $\alpha, \alpha$-dialkylated aldehyde $1 \mathbf{k}$ with 1 -octene using a dppm-derived catalyst provided alkene hydroacylation adduct $\mathbf{5 b}$ in $73 \%$ yield. A final optimization proved that complete conversion to the desired product was possible if an excess of alkene was used in combination with $5 \mathrm{~mol} \%$ of a preformed dcpm catalyst.

These optimized conditions were applicable to a wide variety of alkenes, and in all cases excellent yields of the hydroacylation adducts were obtained (Table 4). Several useful functional groups could be introduced, including ketones, esters, amines, hydroxyl, and halide $(\mathbf{5 f}-\mathbf{l})$. Interestingly, a styryl derivative could be successfully used in these reactions, providing ketone 5m. Styrenes have been a particularly challenging class of alkene to use with earlier generations of chelating aldehydes. ${ }^{4 k, 11 a, b, 22}$ A number of disubstituted alkene substrates were also explored; however, both 1,1- and 1,2-disubstituted examples were unreactive under these conditions. A variety of aldehydes were explored, including examples with different substituents in the nitrogen atom or in the $\alpha$-position $(5 \mathbf{n}-\mathbf{s})$. Aldehydes containing a free $\mathrm{N}-\mathrm{H}$ or a cyclic core also performed well in the reaction with alkenes. Similar to our earlier observations with alkynes, when performing reactions at a larger scale the catalyst loading could be decreased to $1 \mathrm{~mol} \%$ without any effect on the reactivity (5e).

Having established that amides could be exploited to control alkyne and alkene hydroacylation processes, we set about exploring the use of alternative carbonyl-derived directing groups. We began with the synthesis of the ethyl ester counterpart of our standard $\beta$-amido aldehyde 1a. However, it soon became apparent that this ester was inactive in the targeted reactions. We attributed this lack of reactivity to the $\beta$ ester substrate existing predominantly as the enol tautomer (as seen by ${ }^{1} \mathrm{H}$ NMR spectroscopy). In comparison, all of the $\beta$ amido aldehydes we had prepared existed in their respective keto forms. To remove this issue we prepared an $\alpha, \alpha$ disubstituted variant, which by design could only exist in the keto form. When the dialkylated ester was subjected to our optimal conditions for the hydroacylation of amido aldehyes with terminal alkynes, the corresponding linear product was obtained with good control of regioselectivity and in an 
Table 4. Hydroacylation of Alkenes Using $\beta$-Amido Aldehydes $^{a}$

$$
\text { (1) }
$$

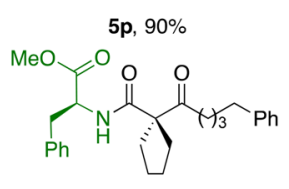

${ }^{a}$ Reaction conditions: 1 (1.0 equiv), alkene (3.0 equiv), $[\mathrm{Rh}(\mathrm{dcpm})$ $\left.\left(\mathrm{C}_{6} \mathrm{H}_{5} \mathrm{~F}\right)\right]\left[\mathrm{BAr}_{4}^{\mathrm{F}}\right](5 \mathrm{~mol} \%)$, acetone $[2.0 \mathrm{M}], 55^{\circ} \mathrm{C}, 18 \mathrm{~h} . \mathrm{Ar}^{\mathrm{F}}=$ $\mathrm{C}_{6} \mathrm{H}_{3}-3,5-\left(\mathrm{CF}_{3}\right)_{2}$. Isolated yields. Single regiosomers. ${ }^{b} 7.5 \mathrm{~mol} \%$ catalyst.

excellent $90 \%$ yield (Table 5, 8a). Variation of the cyclopentyl group on the $\alpha$-carbon atom to a methyl-benzyl or methylbutyl arrangement did not affect the reactivity significantly, with the corresponding linear adducts obtained in high yields (entries $\mathbf{8 b}, \mathbf{c}$ ).

Ketones were the final class of carbonyl compounds to be explored. Similar to the ester series, monosubstituted $\beta$-keto aldehydes also exhibited a significant enol component, and we again decided to use dialkylation to block this. To our delight, when the corresponding $\alpha, \alpha$-disubstituted $\beta$-keto aldehyde was subjected to the reaction with 1-octyne, employing our optimal conditions, the hydroacylation product was obtained in an impressive isolated yield of $95 \%$ (8d). This result was successfully extended to several alternative alkynes of varying steric demand and featuring a range of functional groups $(\mathbf{8 e}-$ j). In addition, variation of the substituents in either the $\alpha$ - or $\alpha^{\prime}$-position of the ketones proved possible $(\mathbf{8 k}-\mathbf{n})$.

To illustrate the synthetic potential of the developed chemistry we briefly explored its use in heterocycle synthesis and combined the use of amido aldehyde substrates with various heterocycle-forming methods previously developed in our laboratories (Scheme 4)..$^{14 a-d}$ Amido aldehydes were combined, using the standard reaction conditions, with three alkynes containing functional groups designed to promote heterocycle formation. Following hydroacylation, the adducts
Table 5. Hydroacylation of $\beta$-Formyl Esters and $\beta$-Keto Aldehydes $^{a}$

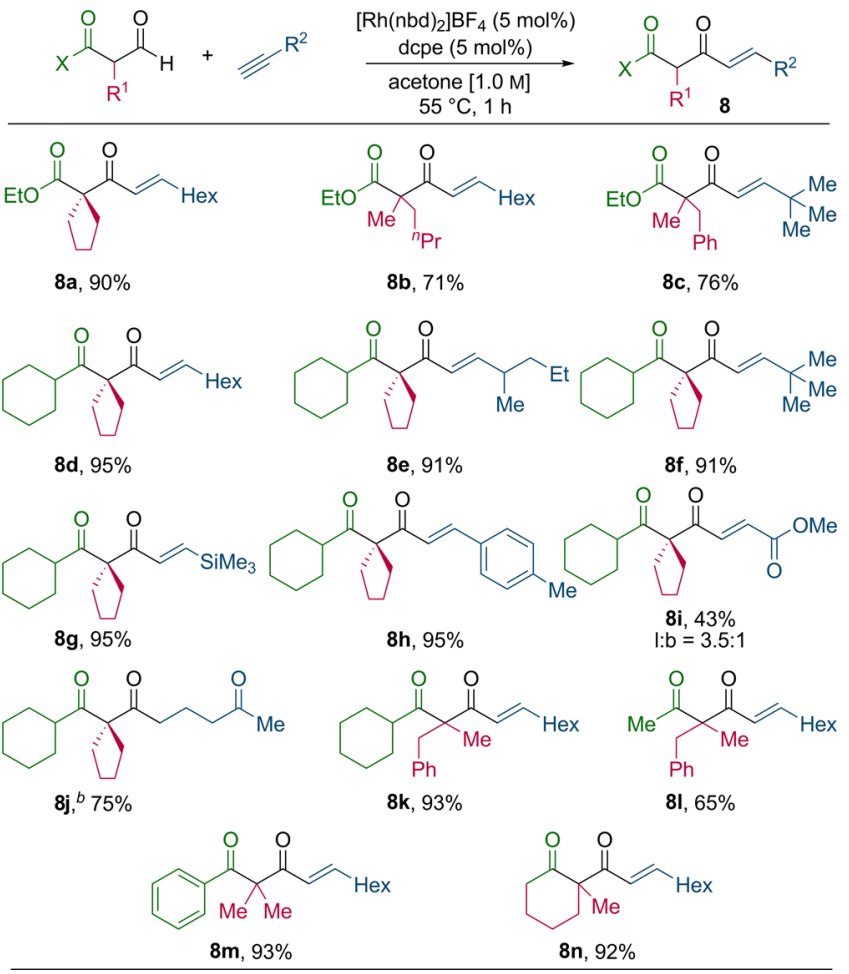

${ }^{a}$ Reaction conditions: aldehyde (1.0 equiv), alkyne (1.2 equiv), $\left[\mathrm{Rh}(\mathrm{nbd})_{2}\right] \mathrm{BF}_{4}(5 \mathrm{~mol} \%)$, dcpe $(5 \mathrm{~mol} \%)$, acetone $[1.0 \mathrm{M}], 55^{\circ} \mathrm{C}, 1$ h. Isolated yields of single isomers. ${ }^{b} 3$-Butyn-2-ol used as substrate.

Scheme 4. Application to the Synthesis of Heterocycles
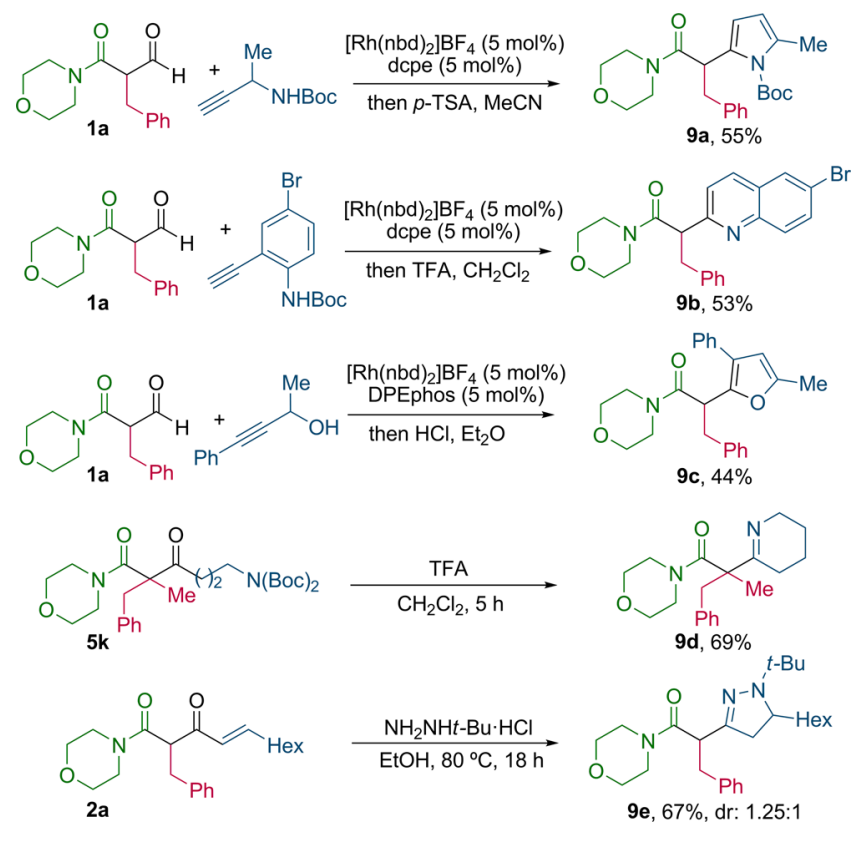

were subjected to the published cyclization conditions, to deliver pyrrole 9a, quinoline $9 \mathrm{~b}$, and furan 9c. In addition, the alkene hydroacylation adduct $\mathbf{5 k}$ was converted into tetrahydropyridine 9d by treatment with TFA. Finally, enone 2a was combined with $t$-Bu-hydrazine to provide dihydropyrazole $9 \mathbf{e}$.

The results presented in this report demonstrate that $\beta$ carbonyl-substituted aldehydes are exceptional substrates for a 
broad range of $\mathrm{Rh}$-catalyzed hydroacylation reactions. Given the success of these substrates, it was of interest to explore whether the $\beta$-carbonyl-substituted aldehydes coordinate to rhodium in an analogous manner to $\beta$-S-aldehydes, despite possessing attenuated donating ability. In order to observe potentially reactive intermediates, the moderately active Xantphos catalyst system (Scheme 2) was selected for the initial studies, in the anticipation that this ligand, which shows less flexibility than DPEphos, would enable intermediate species to be observed. We have previously demonstrated such changes in activity in the hydroacylation of $\beta$-S aldehydes. ${ }^{10 a}$ Addition of 1 equiv of the $\beta$-amido aldehyde (1j) to an acetone solution of the $\mathrm{Rh}(\mathrm{I})$ precatalyst $\left[\mathrm{Rh}\left(\kappa^{3}-\mathrm{P}, \mathrm{O}, \mathrm{P}-\mathrm{X}\right.\right.$ antphos $\left.)\left(\eta^{2}-\mathrm{PhCCPh}\right)\right]\left[\mathrm{BAr}^{\mathrm{F}}{ }_{4}\right]\left(10 \mathrm{a}, \mathrm{Ar}^{\mathrm{F}}=3,5-\right.$ $\left.\left(\mathrm{CF}_{3}\right)_{2} \mathrm{C}_{6} \mathrm{H}_{3}\right)^{23}$ resulted in an immediate color change from red to pale yellow and complete conversion to a new complex as indicated by ${ }^{31} \mathrm{P}\left\{{ }^{1} \mathrm{H}\right\}$ NMR spectroscopy (Figure 1). Upon

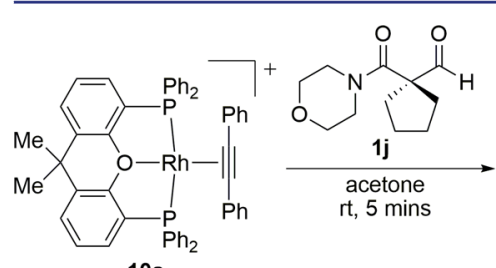

$10 \mathrm{a}$

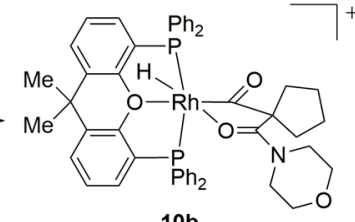

$10 \mathrm{~b}$

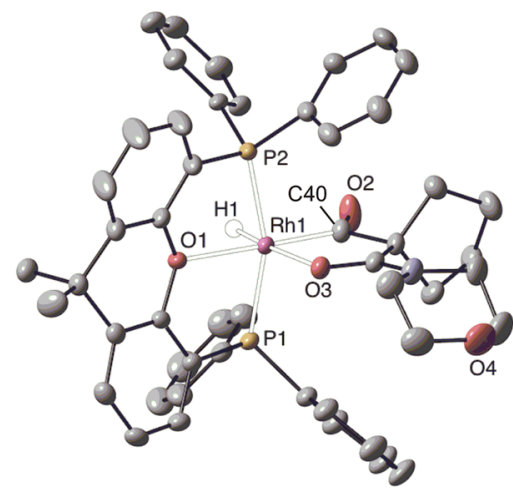

Figure 1. Synthesis of complex $10 \mathrm{~b}$ and solid-state structure. Displacement ellipsoids are shown at the $50 \%$ probability level. Selected bond distances $(\AA)$ and angles (deg): Rh1-H1, 1.45(2); Rh1-O1, 2.2895(10); Rh1-O3, 2.1584(10); Rh1-C40, 1.9408(16); Rh1-P1, 2.2803(4); Rh1-P2, 2.2702(4); P1-Rh1-P2, 160.651(14). $\left[\mathrm{BAr}_{4}^{\mathrm{F}}\right]^{-}$anions are not shown.

isolation by recrystallization from 1,2-difluorobenzene/pentane the complex was identified as the $\mathrm{Rh}$ (III) $\beta$-amido-acylhydride complex $\left[\mathrm{Rh}\left(m e r-\kappa^{3}{ }_{-\mathrm{p}, \mathrm{O}, \mathrm{P}}-\mathrm{Xantphos}\right)(\mathrm{H})\left(\mathrm{COC}\left\{\mathrm{C}_{4} \mathrm{H}_{8}\right\} \mathrm{CO}-\right.\right.$ $\left.\left.\left\{\mathrm{OC}_{4} \mathrm{H}_{8} \mathrm{~N}\right\}\right)\right]\left[\mathrm{BAr}_{4}{ }_{4}\right](\mathbf{1 0 b})$ by NMR spectroscopy and single-crystal X-ray diffraction. These data show that $\mathrm{C}-\mathrm{H}$ activation of the aldehyde has occurred to give a $\mathrm{Rh}(\mathrm{III})-$ acylhydride with a supporting $\beta$-amide $\mathrm{Rh} \cdots \mathrm{O}$ interaction. The solid-state structure of $\mathbf{1 0 b}$ is shown in Figure 1. The Xantphos ligand adopts a $m e r-\kappa^{3}{ }_{-\mathrm{p}, \mathrm{O}, \mathrm{P}}$-Xantphos geometry with the acyl group sitting trans to the Xantphos ligand's oxygen atom [Rh1-C40, 1.9408(16); Rh1-O1, 2.2895(10) A] , while the $\beta$ amido group sits trans to the hydride [Rh1-O3, 2.1584(10)]. The hydride ligand was located and freely refined. In the ${ }^{1} \mathrm{H}$ NMR spectrum the hydride is observed at $\delta-14.7$ as a doublet of triplets $[J(\mathrm{RhH})=27.2 ; J(\mathrm{PH})=9.3 \mathrm{~Hz}]$; the ${ }^{31} \mathrm{P}\left\{{ }^{1} \mathrm{H}\right\} \mathrm{NMR}$ spectrum displays a single environment at $\delta 29[J(\mathrm{RhP})=128$
$\mathrm{Hz}]$; while in the ${ }^{13} \mathrm{C}\left\{{ }^{1} \mathrm{H}\right\}$ NMR spectrum the acyl group is observed at $\delta 224.0[J(\mathrm{RhC})=36.7 \mathrm{~Hz} ; J(\mathrm{PC})=5.9 \mathrm{~Hz}]$.

Complex 10b is stable toward reductive decarbonylation, remaining unchanged ( ${ }^{31} \mathrm{P} \mathrm{NMR}$ spectroscopy) when heated to $55{ }^{\circ} \mathrm{C}$ in acetone for $24 \mathrm{~h}$. This is no doubt due to the stabilizing influence that the $\kappa^{3}$-Xantphos ligand has by protecting the cis vacant site necessary for initial carbonyl deinsertion. ${ }^{10 a, 24}$ In addition, the product of carbonyl deinsertion would possess a tertiary $\mathrm{Rh}-\mathrm{CR}_{3}$ bond in a strained 4-membered metallacyclic $\mathrm{Rh}-\mathrm{O}-\mathrm{C}-\mathrm{C}$ ring, which is likely to be unfavored. This could well explain the lack of decarbonylation products observed in alkene hydroacylation using $\alpha, \alpha$-disubstituted aldehydes (Table 4).

Complexes such as $\mathbf{1 0 b}$ are generally accepted as intermediates in $\mathrm{Rh}(\mathrm{I})$-catalyzed hydroacylation, and analogous $\mathrm{Rh}$ (III) $\beta$-S-acylhydride complexes have been shown to afford the products of hydroacylation on addition of the alkene or alkyne. ${ }^{12 a, 25}$ To demonstrate this here, addition of 9 equiv of $\beta$ amido aldehyde $(\mathbf{1 j})$ and 10 equiv of 1 -octyne to $10 \mathbf{b}(0.075$ M) was monitored by ${ }^{1} \mathrm{H}$ NMR spectroscopy at $55{ }^{\circ} \mathrm{C}$ (Scheme 5). After $24 \mathrm{~h}$ partial consumption of aldehyde was observed, to form the linear enone product, 2aa (43\% NMR yield), consistent with the initial results of in situ screening, albeit using a different aldehyde (Scheme 2). In addition to $\mathbf{2 a a}$, a significant amount (39\%) of a 1:0.23 mixture of 1,2,4-tri- $n$ hexylbenzene:1,3,5-tri- $n$-hexylbenzene (11) products formed by

Scheme 5. Reaction Conditions with Catalyst $10 \mathrm{~b},{ }^{a}$ Reaction Profile as Measured by ${ }^{1} \mathrm{H}$ NMR Spectroscopy, ${ }^{b}$ and a Proposed Mechanism for Hydroacylation with Xantphos Catalyst $^{c}$
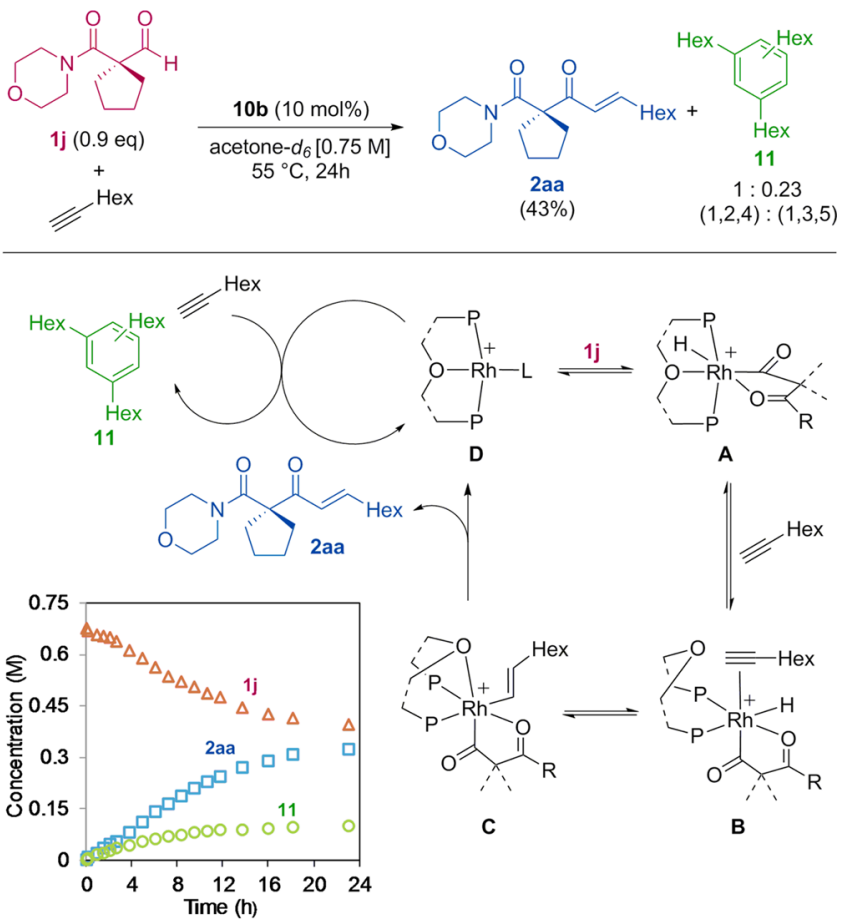

${ }^{a}$ Reaction conditions: aldehyde (1.0 equiv), alkyne (1.0 equiv), NMR yields, ratio of 1,2,4-tri- $n$-hexylbenzene:1,3,5-tri- $n$-hexylbenzene (1:0.23) as determined by ${ }^{1} \mathrm{H}$ NMR. ${ }^{b}$ Time concentration plot for catalysis; aldehyde, 1ab (red triangle), product, 2ab (blue square), benzenes, 10c (green circle). ' Proposed Mechanism: L = e.g., alkyne, Xantphos shown in abbreviated form. 
alkyne cyclotrimerization was observed. A temporal profile for this reaction is shown in Scheme 5, demonstrating that hydroacylation and cyclotrimerization are competitive processes, thus resulting in incomplete consumption of aldehyde in hydroacylation. The catalytic cyclotrimerization of alkynes has previously been reported using the $\mathrm{Rh}(\mathrm{I})$ catalyst $\left[\mathrm{Rh}\left(\kappa^{3}{ }^{3}{ }_{\mathrm{P}, \mathrm{O}, \mathrm{P}^{-}}\right.\right.$ Xantphos $\left.)\left(\eta^{2}-\mathrm{PhCCPh}\right)\right]\left[\mathrm{BAr}_{4}^{\mathrm{F}}\right]$, and this process is also competitive with alkyne carbothiolation using $\beta$-S-aldehydes. ${ }^{23}$

The proposed catalytic cycle (Scheme 5) is based on the observations reported here and previously studied hydroacylation $^{25}$ and Xantphos-ligand ${ }^{23}$ systems. We suggest that the observed product distribution could arise from the relative rates of oxidative addition of aldehyde $1 \mathbf{j}$ to $\mathbf{D}$ compared with overall alkyne trimerization or that one of the subsequent steps up to and including the reductive elimination of the hydroacylation product is slow ${ }^{25 b}$ (i.e., C), and trimerization thus becomes competitive if equilibria are operating. Interestingly, for the DPEphos catalyst competitive cyclotrimerization is not observed, consistent with the higher yields obtained in the initial ligand evaluation (Scheme 2). A detailed mechanistic study probing these observations will follow.

\section{CONCLUSIONS}

We have developed the $\mathrm{Rh}(\mathrm{I})$-catalyzed carbonyl-directed hydroacylation of alkynes and alkenes. Amide-, ester-, and ketone-substituted aldehydes can all be employed as substrates. The methodology utilizes mild reaction conditions and tolerates the introduction of a wide variety of functional groups, delivering hydroacylation adducts in excellent yields with high levels of linear selectivity. Modification of the catalyst design allows access to branched products from alkyne hydroacylation. We provide structural data to support $\beta$ carbonyl chelation. The $\beta$-carbonyl-substituted aldehydes we introduce in this report combine extraordinary reactivity with rich synthetic utility and, as such, remove the principal limitation of chelation-controlled hydroacylation methods.

\section{ASSOCIATED CONTENT}

\section{(S Supporting Information}

The Supporting Information is available free of charge on the ACS Publications website at DOI: 10.1021/jacs.7b05713.

CIF file for $\mathrm{Rh}_{1} \mathrm{P}_{2} \mathrm{O}_{4} \mathrm{~B}_{1} \mathrm{~N}_{1} \mathrm{C}_{82} \mathrm{~F}_{24} \mathrm{H}_{61}$ (CIF)

Experimental procedures and supporting characterization data and spectra (PDF)

\section{AUTHOR INFORMATION}

\section{Corresponding Author}

*E-mail: michael.willis@chem.ox.ac.uk.

ORCID

Andrew S. Weller: 0000-0003-1646-8081

Michael C. Willis: 0000-0002-0636-6471

\section{Notes}

The authors declare no competing financial interest.

\section{ACKNOWLEDGMENTS}

This work was supported by the EPSRC (EP/K024205/1, EP/ M024210/1), the EPSRC Centre for Doctoral Training in Synthesis for Biology and Medicine (EP/L015838/1, to J.B.S.), ERC Marie Curie Actions (DEGENHA 656493, to M.F.), and the Clarendon fund of the University of Oxford (T.J.C.).

\section{REFERENCES}

(1) Reviews: (a) Chen, Z.; Wang, B.; Zhang, J.; Yu, W.; Liu, Z.; Zhang, Y. Org. Chem. Front. 2015, 2, 1107. (b) Davies, H. M.; Morton, D. J. Org. Chem. 2016, 81, 343. (c) Gensch, T.; Hopkinson, M. N.; Glorius, F.; Wencel-Delord, J. Chem. Soc. Rev. 2016, 45, 2900. (d) Hartwig, J. F. J. Am. Chem. Soc. 2016, 138, 2. (e) Li, J. J. C-H Bond Activation in Organic Synthesis; CRC Press, 2015.

(2) Reviews: (a) Jun, C.-H.; Jo, E.-A.; Park, J.-W. Eur. J. Org. Chem. 2007, 1869. (b) Ghosh, A.; Johnson, K. F.; Vickerman, K. L.; Walker, J. A.; Stanley, L. M. Org. Chem. Front. 2016, 3, 639.

(3) For a review, see: Leung, J. C.; Krische, M. J. Chem. Sci. 2012, 3, 2202.

(4) Selected examples: Rh: (a) Marder, T. B.; Roe, D. C.; Milstein, D. Organometallics 1988, 7, 1451. (b) Roy, A. H.; Lenges, C. P.; Brookhart, M. J. Am. Chem. Soc. 2007, 129, 2082. Ru: (c) Chen, Q.-A.; Cruz, F. A.; Dong, V. M. J. Am. Chem. Soc. 2015, 137, 3157. (d) Kim, J.; Yi, C. S. ACS Catal. 2016, 6, 3336. (e) Omura, S.; Fukuyama, T.; Horiguchi, J.; Murakami, Y.; Ryu, I. J. Am. Chem. Soc. 2008, 130, 14094. (f) Shibahara, F.; Bower, J. F.; Krische, M. J. J. Am. Chem. Soc. 2008, 130, 14120. (g) Williams, V. M.; Leung, J. C.; Patman, R. L.; Krische, M. J. Tetrahedron 2009, 65, 5024. Co: (h) Chen, Q. A.; Kim, D. K.; Dong, V. M. J. Am. Chem. Soc. 2014, 136, 3772. (i) Lenges, C. P.; Brookhart, M. J. Am. Chem. Soc. 1997, 119, 3165. Ni: (j) Tsuda, T.; Kiyoi, T.; Saegusa, T. J. Org. Chem. 1990, 55, 2554. (k) Xiao, L.-J.; Fu, X.-N.; Zhou, M.-J.; Xie, J.-H.; Wang, L.-X.; Xu, X.-F.; Zhou, Q.-L. J. Am. Chem. Soc. 2016, 138, 2957.

(5) $\mathrm{Ru}$ catalysts: (a) Kokubo, K.; Miura, M.; Nomura, M. Organometallics 1995, 14, 4521. (b) Hong, Y. T.; Barchuk, A.; Krische, M. J. Angew. Chem., Int. Ed. 2006, 45, 6885. Cu catalysts: (c) Bandar, J. S.; Ascic, E.; Buchwald, S. L. J. Am. Chem. Soc. 2016, 138, 5821. (d) Zhou, Y.; Bandar, J. S.; Buchwald, S. L. J. Am. Chem. Soc. 2017, 139, 8126.

(6) Vora, K. P.; Lochow, C. F.; Miller, R. G. J. Organomet. Chem. 1980, 192, 257

(7) Lee, H.; Jun, C. H. Bull. Korean Chem. Soc. 1995, 16, 66.

(8) (a) Coulter, M. M.; Kou, K. G. M.; Galligan, B.; Dong, V. M. J. Am. Chem. Soc. 2010, 132, 16330. (b) Du, X.-W.; Stanley, L. M. Org. Lett. 2015, 17, 3276. (c) Imai, M.; Tanaka, M.; Tanaka, K.; Yamamoto, Y.; Imai-Ogata, N.; Shimowatari, M.; Nagumo, S.; Kawahara, N.; Suemune, H. J. Org. Chem. 2004, 69, 1144. (d) Kokubo, K.; Matsumasa, K.; Miura, M.; Nomura, M. J. Org. Chem. 1997, 62, 4564. (e) Murphy, S. K.; Petrone, D. A.; Coulter, M. M.; Dong, V. M. Org. Lett. 2011, 13, 6216.

(9) (a) Castaing, M.; Wason, S. L.; Estepa, B.; Hooper, J. F.; Willis, M. C. Angew. Chem., Int. Ed. 2013, 52, 13280. (b) Jun, C.-H.; Lee, H.; Hong, J.-B.; Kwon, B.-I. Angew. Chem., Int. Ed. 2002, 41, 2146. (c) Jun, C. H.; Hong, J. B.; Kim, Y. H.; Chung, K. Y. Angew. Chem., Int. Ed. 2000, 39, 3440. (d) Zhang, T.; Qi, Z.; Zhang, X.; Wu, L.; Li, X. Chem. Eur. J. 2014, 20, 3283.

(10) (a) Pawley, R. J.; Moxham, G. L.; Dallanegra, R.; Chaplin, A. B.; Brayshaw, S. K.; Weller, A. S.; Willis, M. C. Organometallics 2010, 29, 1717. (b) Willis, M. C.; Woodward, R. L. J. Am. Chem. Soc. 2005, 127, 18012. (c) Hooper, J. F.; Seo, S.; Truscott, F. R.; Neuhaus, J. D.; Willis, M. C. J. Am. Chem. Soc. 2016, 138, 1630. For an intramolecular example, see: (d) Bendorf, H. D.; Colella, C. M.; Dixon, E. C.; Marchetti, M.; Matukonis, A. N.; Musselman, J. D.; Tiley, T. A. Tetrahedron Lett. 2002, 43, 7031.

(11) (a) Murphy, S. K.; Bruch, A.; Dong, V. M. Angew. Chem., Int. Ed. 2014, 53, 2455. (b) Murphy, S. K.; Bruch, A.; Dong, V. M. Chem. Sci. 2015, 6, 174. (c) Tanaka, K.; Shibata, Y.; Suda, T.; Hagiwara, Y.; Hirano, M. Org. Lett. 2007, 9, 1215.

(12) (a) Gonzalez-Rodriguez, C.; Pawley, R. J.; Chaplin, A. B.; Thompson, A. L.; Weller, A. S.; Willis, M. C. Angew. Chem., Int. Ed. 2011, 50, 5134. (b) Zhang, H.-J.; Bolm, C. Org. Lett. 2011, 13, 3900.

(13) Phan, D. H. T.; Kou, K. G. M.; Dong, V. M. J. Am. Chem. Soc. 2010, 132, 16354.

(14) (a) Majhail, M. K.; Ylioja, P. M.; Willis, M. C. Chem. - Eur. J. 2016, 22, 7879. (b) Neuhaus, J. D.; Morrow, S. M.; Brunavs, M.; Willis, M. C. Org. Lett. 2016, 18, 1562. (c) Lenden, P.; Entwistle, D. 
A.; Willis, M. C. Angew. Chem., Int. Ed. 2011, 50, 10657. (d) von Delius, M.; Le, C. M.; Dong, V. M. J. Am. Chem. Soc. 2012, 134, 15022. (15) For the use of an in situ generated directing group, see refs $9 \mathrm{~b}$ and $\mathrm{c}$.

(16) (a) Hooper, J. F.; Chaplin, A. B.; Gonzalez-Rodriguez, C.; Thompson, A. L.; Weller, A. S.; Willis, M. C. J. Am. Chem. Soc. 2012, 134, 2906. (b) Hooper, J. F.; Young, R. D.; Pernik, I.; Weller, A. S.; Willis, M. C. Chem. Sci. 2013, 4, 1568.

(17) (a) Ilies, L.; Chen, Q.; Zeng, X.; Nakamura, E. J. Am. Chem. Soc. 2011, 133, 5221. (b) Li, G.; Wan, L.; Zhang, G.; Leow, D.; Spangler, J.; Yu, J. Q. J. Am. Chem. Soc. 2015, 137, 4391. (c) Mehta, V. P.; Garcia-Lopez, J. A.; Greaney, M. F. Angew. Chem., Int. Ed. 2014, 53, 1529. (d) Patureau, F. W.; Besset, T.; Glorius, F. Angew. Chem., Int. Ed. 2011, 50, 1064. (e) Schroder, N.; Wencel-Delord, J.; Glorius, F. J. Am. Chem. Soc. 2012, 134, 8298. (f) Wang, D. H.; Engle, K. M.; Shi, B. F.; Yu, J. Q. Science 2010, 327, 315. (g) Kim, J.; Chang, S. Angew. Chem., Int. Ed. 2014, 53, 2203.

(18) Goodman, C. G.; Johnson, J. S. J. Am. Chem. Soc. 2015, 137, 14574.

(19) Chaplin, A. B.; Hooper, J. F.; Weller, A. S.; Willis, M. C. J. Am. Chem. Soc. 2012, 134, 4885.

(20) Prades, A.; Fernandez, M.; Pike, S. D.; Willis, M. C.; Weller, A. S. Angew. Chem., Int. Ed. 2015, 54, 8520.

(21) (a) Sim, Y. K.; Lee, H.; Park, J. W.; Kim, D. S.; Jun, C. H. Chem. Commun. 2012, 48, 11787. (b) Miura, H.; Wada, K.; Hosokawa, S.; Inoue, M. Chem. - Eur. J. 2013, 19, 861.

(22) Yang, J.; Seto, Y. W.; Yoshikai, N. ACS Catal. 2015, 5, 3054.

(23) Ren, P.; Pike, S. D.; Pernik, I.; Weller, A. S.; Willis, M. C. Organometallics 2015, 34, 711.

(24) Goikhman, R.; Milstein, D. Angew. Chem., Int. Ed. 2001, 40, 1119.

(25) (a) Moxham, G. L.; Randell-Sly, H.; Brayshaw, S. K.; Weller, A. S.; Willis, M. C. Chem. - Eur. J. 2008, 14, 8383. (b) Pawley, R. J.; Huertos, M. A.; Lloyd-Jones, G. C.; Weller, A. S.; Willis, M. C. Organometallics 2012, 31, 5650. 